\title{
IMPROVED MECHANICAL PROPERTIES OF AI-Si ALLOYS BY ADDING AN EXTRUSION PROCESS TO CONVENTIONAL PROCESSING METHOD
}

\begin{abstract}
In this study, the mechanical properties of Al-Si alloys was improved by selecting higher Si content and avoiding distortion in Al-Si matrix by adding an extrusion process such that the fabrication processes casting and extrusion were in sequence. Cast billets were extruded at ratios 4:1 and 10:1 to obtained two extruded bars with different processing parameters. The as-extruded samples were characterized and investigated for microstructure and mechanical properties. Optical Microscope was used to examined phase morphologies and microstructures of the extruded Al-Si bars. Mechanical properties were conducted on each sample to study the effectiveness of the additional extrusion process in high Si content Al-Si alloys. The result shows that by increasing the extrusion ratio, the size of the primary Si particle reduces leading to a higher density, better tensile and yield strength compared to the cast billet.

Keywords: Al-Si alloys, extrusion, mechanical properties
\end{abstract}

\section{Introduction}

Recently, to meet the necessities of low energy consumption in automotive and aviation industries, aluminum and its alloys used as structure materials have taken the place of ferrous alloys in many situations because they are low cost, have low density and high specific strength. Among the aluminum alloys, Al-Si alloys are commonly used in engine parts because high content of Si lowers the cost of raw materials, improves the castability, and maintains high specific strength, good corrosion resistance, and weldability [1-4]. The size and morphology of silicon phases in Al-Si alloys play a critical role in determining the mechanical properties of the alloys. The main strategy to improve the mechanical properties of Al-Si alloys is modification of the shape and size of Si phases together with refinement in the Al-matrix. Hence, to obtained modified and refined microstructure for the sake of better mechanical properties, numerous techniques, such as adding element $\mathrm{Sc}, \mathrm{Sr}, \mathrm{Al}$ and $\mathrm{P}$ to the melt, gas atomization, melt spinning, die forging, hot forging technology, has been presented in the literature [5-6]. However, improvement of strength generally leads to a decrease in ductility. To obtain an increased strength whiteout losing ductility, recently, much attention has been paid to the severe plastic deformation to obtain fine-grained materials suitable for better strength and ductility because of Hall-Petch effect. It has been reported that mechanical properties, such as yield strength, ultimate tensile strength, and elongation could be improved by severe plastic deformation caused by techniques such as extrusion, mechanical milling, rotary-die equal channel angular pressing [7-9]. Therefore, In this study, extrusion processes of Al-Si alloy at different extrusion ratios were performed.

\section{Experimental}

Pure element of $99.9999 \%$ purity in the stoichiometric ratio as shown in Table 1 were measured and melted in an induction furnace at high temperature. The molten alloy was then poured into a mold to produce a 13 inches diameter billet. The billets were then extruded into a bar at an extrusion temperature of $400^{\circ} \mathrm{C}$ with a ramp speed of $4.5 \mathrm{~mm} / \mathrm{s}$ and an exit temperature of $410^{\circ} \mathrm{C}$. Two extrusion ratios of $4: 1$ and $10: 1$ were chosen to study the effects of the additional extrusion process on the microstructure and mechanically properties of the cast billets. Two sections of the as-extruded bar and the cast billet was cut and polished for microstructure examinations in both the cross and longitudinal directions. A Keller's reagent comprising of $190 \mathrm{ml}$ distilled water, $5 \mathrm{ml}$ nitric acid, $3 \mathrm{ml}$ hydrochloric acid and $2 \mathrm{ml}$ hydrofluoric acid was used as an etchant to etch the polished samples so as to reveal the grains size/distribution and morphologies of the microstructure obtained with an Olympus GX41 optical microscope. An image processing software ImageJ was used to estimate the size of the dispersed Si particles in the Al matrix. Tensile test was carried out on an AG-X Plus (ShimadZu) tensile testing equipment with samples dimensions according to the ASTM E8 subsize standard.

\footnotetext{
* DIVISION OF ADVANCED MATERIALS ENGINEERING, KONGJU NATIONAL UNIVERSITY, 1223-24 CHEONAN DAERO, SEOBUK-GU, CHEONAN-SI, CHUNGNAM, 331-717, SOUTH KOREA ** DEPARTMENT OF MATERIALS SCIENCE AND NANOTECHNOLOGY ENGINEERING, KASTAMONU UNIVERSITY, KASTAMONU, TURKEY

*** DONGYANG A.K KOREA CO. LTD, SEJONG, KOREA. 
TABLE 1

Summary of starting composition

\begin{tabular}{|c|c|c|c|c|c|}
\hline \hline Element & Al & Si & $\mathbf{C u}$ & $\mathbf{M g}$ & $\mathbf{F e}$ \\
\hline Content $(\mathrm{Wt} \%)$ & 83 & 9 & 3 & 0.5 & 0.5 \\
\hline
\end{tabular}

\section{Results and discussion}

Fig. 1 shows Optical microscope image of the as-cast alloy at different magnification. The inset illustrates the section of the microstructure (a-b cross-section and c-d longitudinal-section). It is clearly seen from the figure that appearance of aluminum and silicon phases seen in the both sections are very similar, distributions of them are isotropic, and the microstructures exhibit a dendritic morphology with average Silicon size of 5-7 $\mu \mathrm{m}$ in $\mathrm{Al}$ matrix. Mean length and wideness of $\alpha-\mathrm{Al}$ grains are 8 and $22 \mu \mathrm{m}$, respectively.

Figure 2 illustrates optical micrographs obtained from crosssections and longitudinal sections of the as-cast alloy after extrusion at a different extrusion ratio of (4:1 (a-b) and 10:1 (c-d)). One can see from the figure that while the distributions of $\mathrm{Al}$ and $\mathrm{Si}$ phases in the cross-sectional parts are homogeneous and isotropic; in the longitudinal sections, distributions of $\mathrm{Al}$ and $\mathrm{Si}$ phases of the sample extruded at 4:1 are more homogenous than those of the sample extruded at 10:1, and they are not isotropic. Due to high shear force during extrusion, prolonged aluminum grains were obtained, the orientation of which was parallel to the extrusion direction. Extrusion process also changed the aspect ratios of aluminum phases. In both extrusion conditions, while average wideness of aluminum phases did not change so much, their average length increases drastically compared to the as-cast alloy. In the longitudinal sections of the samples extruded at a ratio of 4:1 (Fig. 2b) and 10:1 (Fig. 2d), with the effect of extrusion length of the aluminum phases increased from $22 \mu \mathrm{m}$ to 60 and $115 \mu \mathrm{m}$, respectively. This means that the higher extrusion ratio brings about, the longer aluminum grains for the present Al-Si alloys. As for the Si particles, extrusion process led to a dramatic decrease in the average size of silicon particle. Fig. 3 shows the results of particle size analysis of $\mathrm{Si}$ in the cast + extruded alloys. In the samples extruded at a ratio of $4: 1$ and 10:1, the average size of silicon particles decreased from 5 and $7 \mu \mathrm{m}$ to 3.3 and $3.1 \mu \mathrm{m}$ compared to the as-cast alloy. On the other hand, it can also be deduced that with increasing extrusion ratio, the average size of silicon particles decreased from 3.3 to $3.1 \mu \mathrm{m}$ (Fig. 3). This means that Si particles are broken into tiny particles due to high shear force during the extrusion process $[7,8]$.
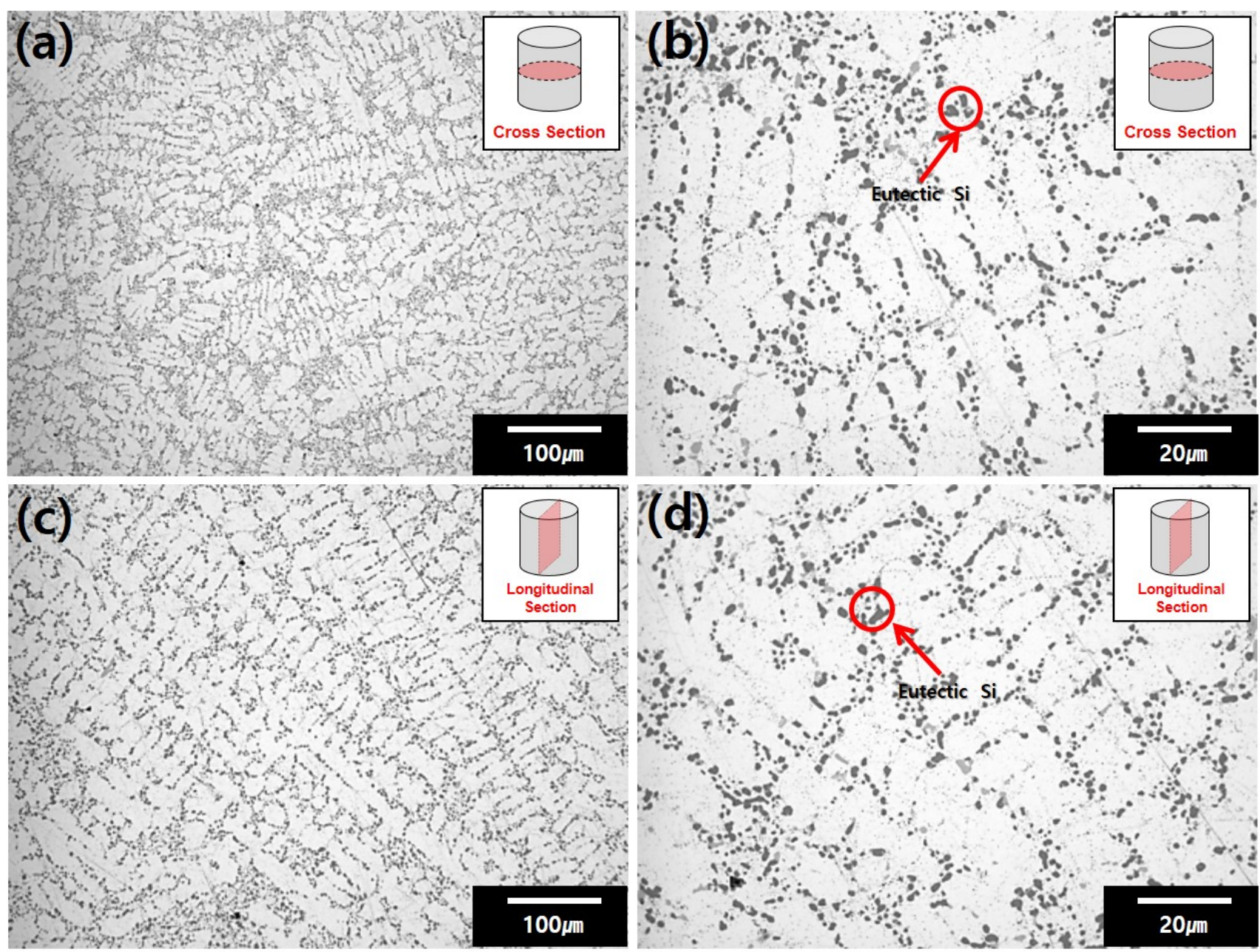

Fig. 1. Optical microscope image of the as-cast alloy at different magnification; the inset shows the section of the microstructure (a-b cross-section and c-d longitudinal-section). The microstructures exhibit a dendritic morphology with average silicon size of 5-7 $\mu \mathrm{m}$ in $\mathrm{Al}$ matrix 

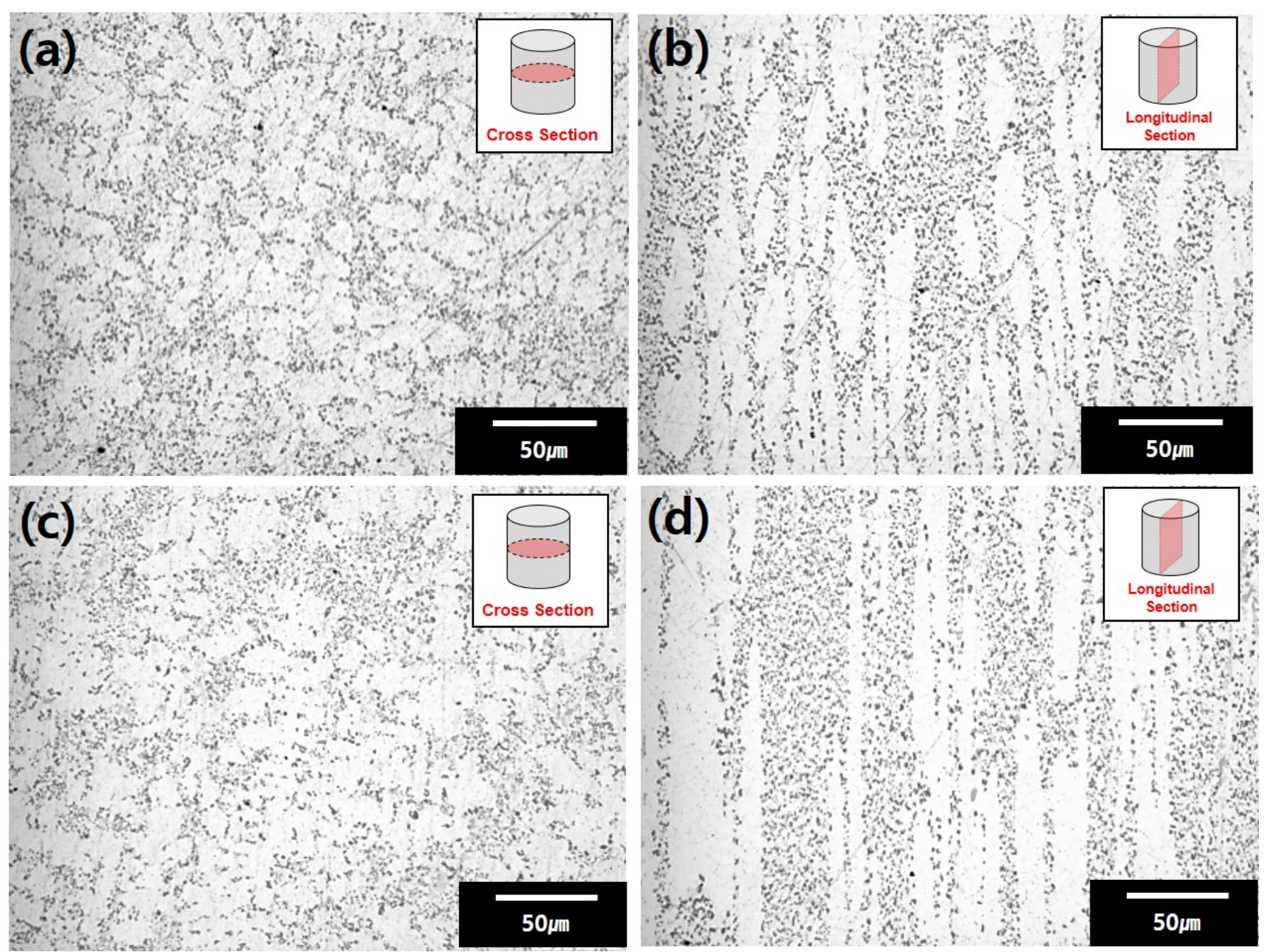

Fig. 2. Optical microscope image of the cast + extruded alloys at different extrusion ratio of 4:1 (a-b) and 10:1 (c-d). The inset shows the section of the microstructure (a-c cross-section and b-d longitudinal-section ). The microstructures exhibit a dendritic morphology with uniformly distributed Si particle with an average size of 3.1-3.3 $\mu \mathrm{m}$. The Si particles are broken into tiny particles due to high shear force during the extrusion process
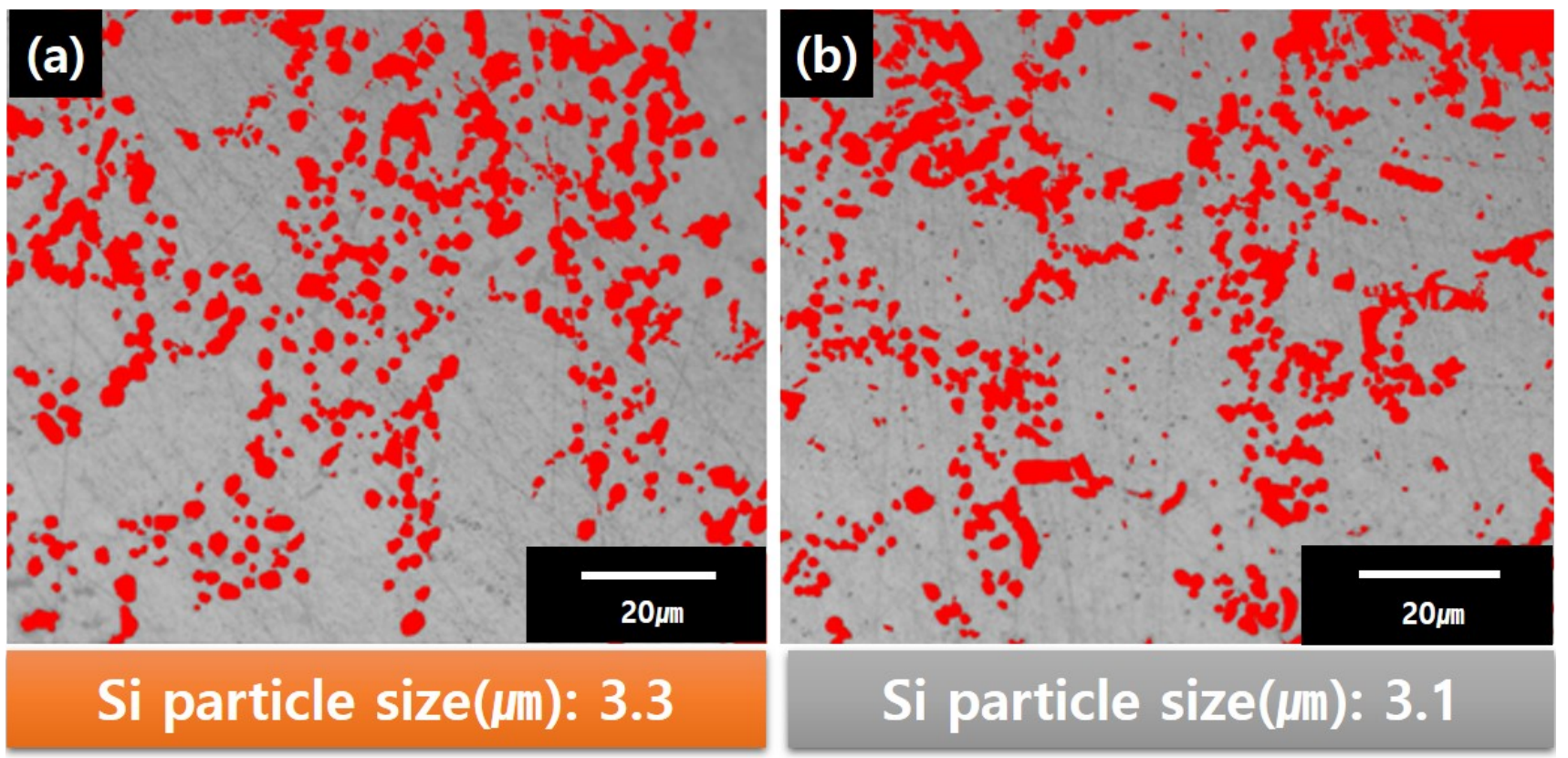

Fig. 3. Particle size analysis of Si in the cast + extruded alloys. (a) 4:1 extrusion ratio and (b) 10:1 extrusion ratio. Results from Image analyzer confirms that increasing extrusion ratio from 4:1 to 10:1 slightly reduced Si particle mean size from 3.3 to 3.1 respectively 
Figure 4 shows changes in the tensile strength of the ascast Al-Si alloy with increasing extrusion rate. From the Fig. 4 it is clearly seen that moderate extrusion rate there did not lead to any changes in the tensile strength of as-cast Al-Si, while severe extrusion rate brought about a considerable increment in it. This was possibly due to the fact that severe extrusion ratio lead to higher density and a refined microstructure (Figs. $2,3)$ because of severe plastic deformation [7]. In Fig. 5, it can also be seen yield strength values of the samples. As it can be seen, extrusion process led to a gradual increase in the yield strength of extruded samples. While, with the effect of extrusion at a ratio of $4: 1$ and 10:1, yield strength values increased from 126 to 194 and $210 \mathrm{MPa}$, respectively. Improvement in mechanical strength in Al-Si alloys can be achieved through strain hardening, grain refinement, solid solution hardening, dispersion hardening and precipitation hardening. Haghdadi et al. [9] reported that in accumulative back extruded Al-Si alloys similar to our experimental route in terms of sever plastic deformations mechanism, except for precipitation hardening other hardening factors can be responsible for strengthening of Al-Si-Mg alloys. In addition, it is well known that the higher extrusion ratios lead to the higher strain rates [9]. Hence, also in our case, a similar explanations can be true for the increment of tensile and yield strength.

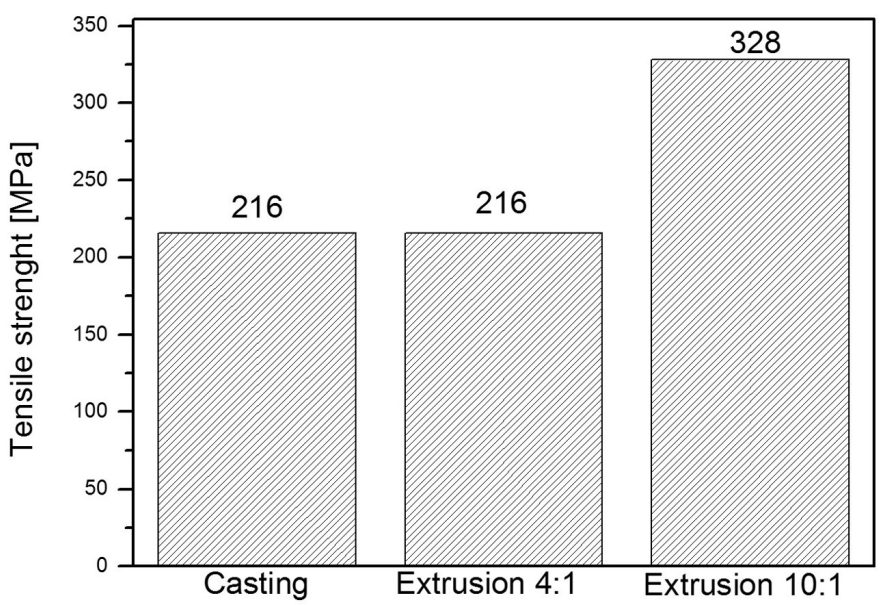

Fig. 4. Tensile strength of as-cast and cast + extrusion alloy at different extrusion ratio. The cast + extrusion alloy at 10:1 shows an improve tensile strength compared to the as-cast alloy due to high density and finer particle size

Fig. 6 shows total elongation rate of the samples. From Fig. 6 it clearly seen that for the present materials, extrusion process had a profound effect on the elongation. Elongation nearly double times increased with the influence of extrusion (for the ratio of $4: 1$ and 10:1 from 4.8 to 9.8 and $8.5 \%$, respectively). However, for the extrusion ratio of $4: 1$, higher elongation was obtained. In Al-Si alloys, the ductility is significantly reflected by the degree of microstructural homogeneity. From Fig. 2, it can be seen that distribution of $\mathrm{Al}$ and $\mathrm{Si}$ phases are more homogenous in the sample extruded at 4:1 (Fig. 2b) than the one extruded at 10:1. Therefore, we think that elongation

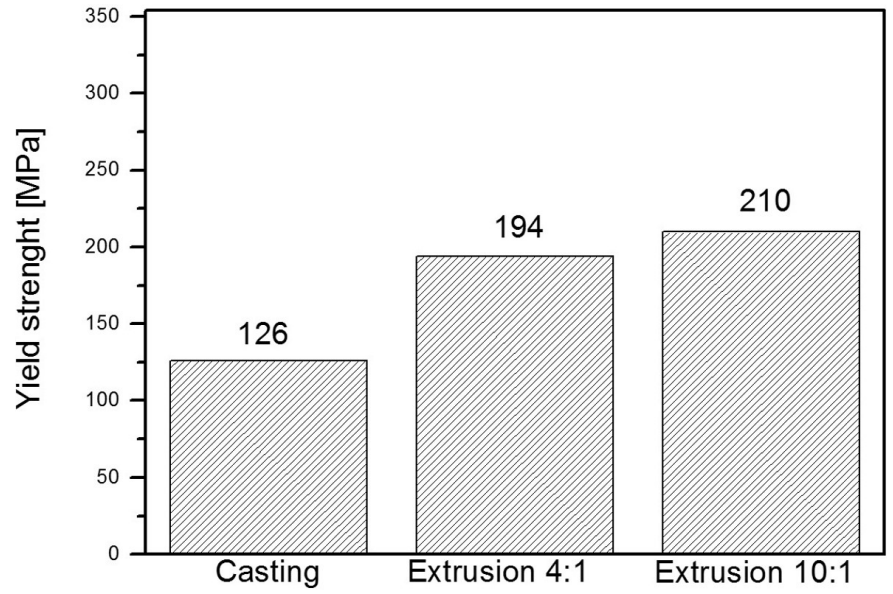

Fig. 5. Yield strength of as-cast and cast + extrusion alloy at different extrusion ratio. The cast + extrusion alloy at 10:1 shows an improve tensile strength compared to the as-cast alloy due to high density and finer particle size

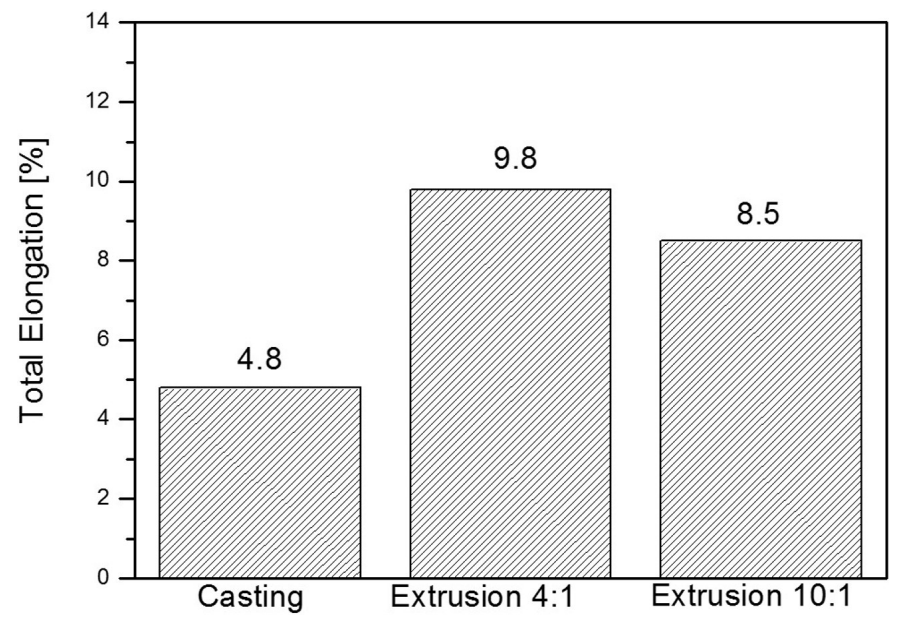

Fig. 6. Total elongation of as-cast and cast + extrusion alloy at different extrusion ratio. The cast + extrusion alloy at 10:1 shows an improve tensile strength compared to the as-cast alloy due to high density and finer particle size

of the sample extruded at 4:1 was better than that of the sample extruded at 10:1 (Fig. 2d) because of more homogenous distribution of $\mathrm{Al}$ and Si particles.

In literature, Al-20Si alloys have UTS values around $200 \mathrm{MPa}$ and elongations ranging from 1 to $4.5 \%$ [10]. In our case, the tensile strength of as - cast and extruded at 4:1 alloys match very well with literature. However, elongation values of extruded samples were considerably higher than those given in literature [10]. The primary and eutectic Si mainly determines the mechanical properties of Al-Si alloys. The cracks are consistently initiated with brittle fracture within the primary $\mathrm{Si}$ or debonding of Si particles from the matrix, and then propagate through the matrix and along the grain boundaries during tension. The refinement of primary silicon can decrease the probability of crack initiation by premature fracture of primary Si particles, and improve the mechanical properties [11]. A reasonably high tensile strength, without the loss of elongation, can be achieved 
in Al-Si alloys by controlling the size of the microstructural features [12]. These results $[11,12]$ are consistent with findings of our study because extrusion process brought about finer $\mathrm{Si}$ particles. Therefore, improvement of mechanical properties for the extruded Al-Si alloys over as-cast Al-20Si alloy can mainly be attributed to the particle size strengthening via Si particles refinement.

\section{Conclusions}

In summary, the present study reports the microstructure and mechanical properties evolution of melt- Al-Si alloy with the effect of extrusion ratio. The conclusions are as follows:

- The higher extrusion ratio brings about, the longer aluminum grains for the present Al-Si alloys,

- Si particles are broken into tiny particles due to high shear force during the extrusion process,

- Extrusion process led to a gradual increase in the yield strength of extruded samples,

- For the present materials, extrusion process had a profound effect on the elongation. Elongation nearly double times increased with the effect of extrusion,

- Improvement of mechanical properties for the extruded Al-Si alloys over as-cast Al-Si alloy can be attributed to the particle size strengthening via Si particles refinement.

\section{Acknowledgment}

This research was supported by the Ministry of Trade, Industry \& Energy (MOTIE), and Korea Institute for Advancement of Technology (KIAT) through the Encouragement Program for The Industries of Economic Cooperation Region.

\section{REFERENCES}

[1] H. Liao, Y. Sun, G. Sun, Mater. Sci. Eng. A 358, 164 (2003).

[2] R. Li, R. Li, Y. Zhao, L. He, C. Li, H. Guan, Z. Hu, Mater. Lett. 58, 2096 (2004).

[3] S.W. Youn, C.G. Kang, Mater. Sci. Eng. A 425, 28 (2006).

[4] Y.N. Kwon, Y.S. Lee, J.H. Lee, J. Mater. Proc. Technol. 187, 533 (2007).

[5] C.D. Lee, Mater. Sci. Eng. A 464, 249 (2007).

[6] M. Zeren, Mater. Des. 28, 2511 (2007).

[7] Y.D. Huang, N. Hort, H. Dieringa, Acta Mater. 53, 3913 (2005).

[8] L. Deng, X. Wang, J. Xia, J. Li, Mat. Sci. Eng. A 528, 6504 (2011).

[9] N. Haghadadi, A. Hanzaki, H.R. Abedi, A. Ras, M. Kawasaki, Mat. Sci. Eng. A 651, 269 (2016).

[10] M.F. Kilicaslan, W.R. Lee, T.H. Lee, Y. Sohn, S.J. Hong, Mater. Lett. 71, 164 (2012).

[11] W. Shi, B. Gao, G. Tu, S. Li, Y. Hao, F. Yu, J. Rare Earths 28, 367 (2010).

[12] S.J. Hong, C.Suryanarayana, Metall. Mater. Trans. A 36, 715 (2005). 